\title{
KAPLAN Lawrence J., SHATZ David, eds., Rabbi Abraham Isaac Kook and Jewish Spirituality
}

New York-Londres, New York University Press, 1995, 346 p. (bibliogr., index)

\section{Régine Azria}

\section{(2) OpenEdition}

\section{Journals}

Édition électronique

URL : http://journals.openedition.org/assr/20658

DOI : $10.4000 /$ assr. 20658

ISSN : $1777-5825$

Éditeur

Éditions de l'EHESS

\section{Édition imprimée}

Date de publication : 1 juillet 2000

Pagination : 120-121

ISBN : 2-222-96691-4

ISSN : 0335-5985

Référence électronique

Régine Azria, « KAPLAN Lawrence J., SHATZ David, eds., Rabbi Abraham Isaac Kook and Jewish Spirituality ", Archives de sciences sociales des religions [En ligne], 110 | avril-juin 2000, document 110-71, mis en ligne le 19 août 2009, consulté le 21 septembre 2020. URL : http:// journals.openedition.org/assr/20658; DOI : https://doi.org/10.4000/assr.20658

Ce document a été généré automatiquement le 21 septembre 2020

(c) Archives de sciences sociales des religions 


\section{KAPLAN Lawrence J., SHATZ David, eds., Rabbi Abraham Isaac Kook and Jewish Spirituality}

New York-Londres, New York University Press, 1995, 346 p. (bibliogr., index)

\section{Régine Azria}

\section{RÉFÉRENCE}

KAPLAN (Lawrence J.), SHATZ (David), eds., Rabbi Abraham Isaac Kook and Jewish Spirituality, New York-Londres, New York University Press, 1995, 346 p. (bibliogr., index)

Paru il y a cinq ans déjà, ce recueil est le fruit de Conférences tenues en 1985-1986 à l'occasion du cinquantenaire de la mort du rav Kook, lequel fut le premier grand rabbin ashkénaze de Palestine. Il rassemble les textes produits à cette occasion par d'éminents spécialistes et regroupés en trois parties : 1) Le rav Kook et les différents courants de la tradition juive (mystique, philosophie, poésie de la spiritualité, halakhah et rédemption) ; 2) Foi, culture et pluralisme : la perspective de l'harmonie (questions de la tolérance et du doute) ; 3) Sionisme, messianisme et État d'Israël. Mort en 1935, donc avant la grande catastrophe de la shoah, le rav Kook n'a pas connu l'État d'Israël. L'ouvrage s'achève sur un texte dont le titre porte la question : qu'aurait eu à dire le rav Kook à propos de l'État d'Israël aujourd'hui ? Pour qui a eu l'occasion de lire certains de ses écrits, il semble peu probable qu'il aurait adhéré aux thèses extrémistes de ceux qui aujourd'hui se réclament de sa pensée. 